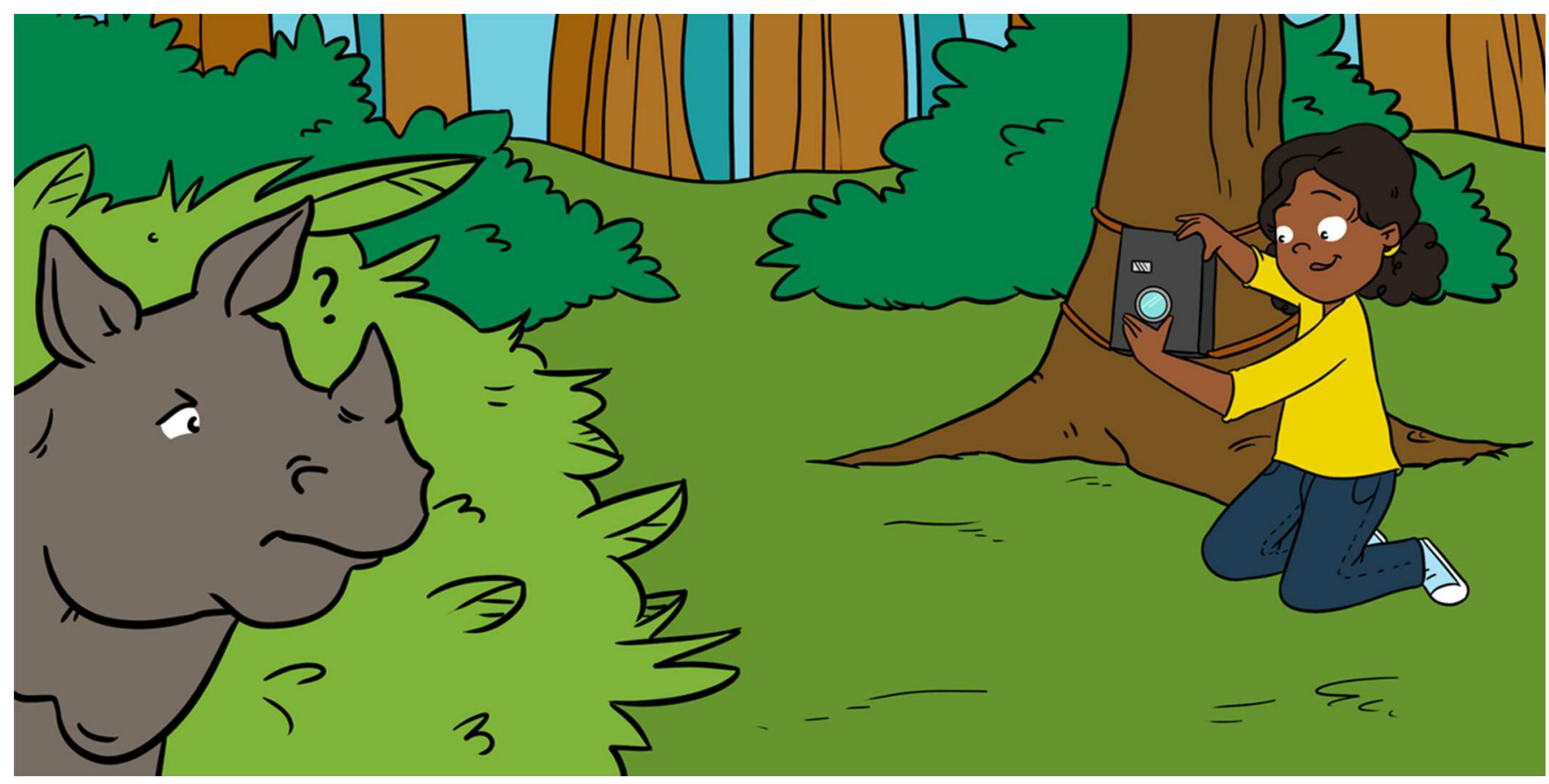

\title{
THE MYSTERIOUS CASE OF THE DISAPPEARING JAVAN RHINO: USING CLUES FROM RHINOS" EVERYDAY HABITS AND HOBBIES TO FIGURE OUT HOW TO HELP THEM RECOVER
}

\section{Erin Rose Harrington * and Brian Daniel Gerber}

Department of Natural Resources Science, University of Rhode Island, Kingston, RI, United States

YOUNG REVIEWERS:

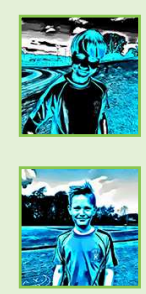

FAZZ

AGE: 11

LYALL

AGE: 11
Javan Rhinos are interesting and mysterious creatures. These rhinos used to live all throughout Northeast India and Southeast Asia. But, the rainforests they need are disappearing. This loss of their habitat, in addition to human development and hunting, are the main reasons they are now only in one spot in the world. A few scientists put on their detective thinking caps and came up with the idea of using "camera traps" to count rhinos. The scientist-detectives ended up getting 1,660 video clips of Javan rhinos from these cameras. Based on the clues they got, they estimated that there are 62 rhinos in the park. Now that the scientist-detectives have a solid estimate about the size of the population, the different ages and sexes of the rhinos, and where they like to hang out, we can come up with a plan to help them recover! 


\section{Figure 1}

Map of large area where Javan rhinos used to live vs. the small area where they live now. Adapted from Groves and Leslie [1].

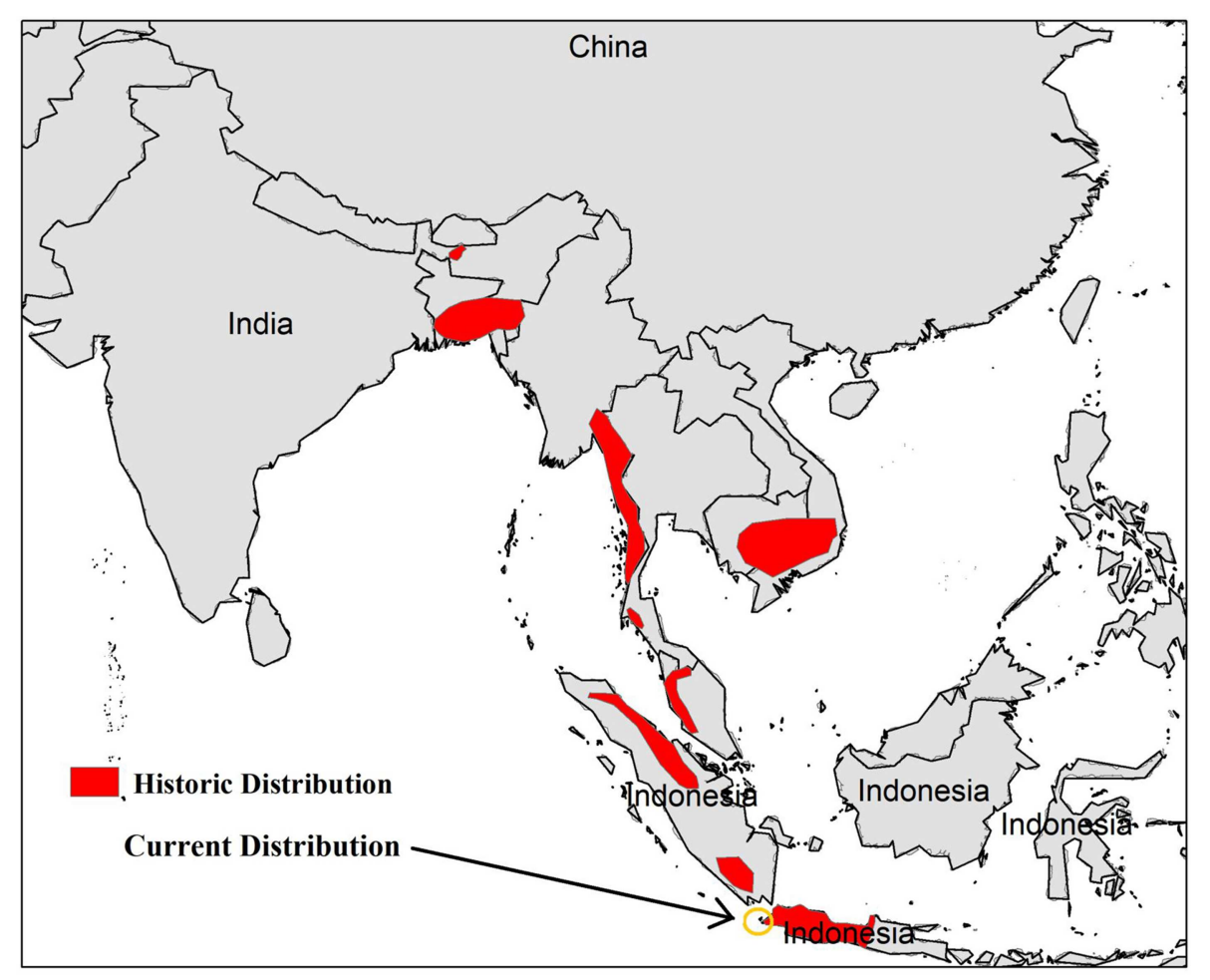

Figure 1

\section{WHAT IS SPECIAL ABOUT JAVAN RHINOS?}

Javan rhinos are interesting and mysterious creatures. They only live in one teeny spot on the island of Java (Indonesia) and are critically endangered. They are really big-somewhere between 4.5 and 5.8 feet tall, and they weigh between 2,000 and 5,000 pounds (that is about the size and weight of a Volkswagon beetle!). But they are secretive animals - so scientists have a really hard time finding them, despite their large size. Perhaps most mysterious though is that the Javan rhino population is disappearing and we are not sure what to do about it.

Javan rhinos used to live all throughout Northeast India and Southeast Asia. In other words, they used to roam an area that was quite large-about the size of Europe. Unlike its rhino cousins in Africa that live in the dry deserts, the Javan rhino needs rainforests. But the rainforests they need are disappearing. This loss of their habitat, in addition to human development and hunting, are the main reasons Javan rhinos are now only found in one spot in the world (Figure 1).

The place that Javan rhinos live is called Ujung Kulon National Park and it is about the size of a large city-think of New York City or London. That is not very much space for a bunch of huge rhinos to live. In order to survive and thrive, Javan rhinos need lots of space to roam around in, plants to eat, and mud to bathe in. Many scientists, conservationists, 
and community members in Indonesia really care about saving the Javan rhino. These people decided the best way to help would be to do scientific research to find out how many Javan rhinos are left, what they need, and where they like to spend their time. So, scientists are on the case to solve this mystery!

\section{HOW DO YOU COUNT RHINOS?}

Counting rhinos is hard work! Think of what would happen if you went into the woods and tried to count all of the birds around you. Some birds would be flying all over the place, and some would hide as soon as they saw you. Other birds would be up in trees and you would never even know they were there. So, if you went into the rainforest and tried to count all the Javan rhinos, you would most likely count zero!

Obviously, rhinos cannot fly, but you get the picture-rhinos can be very secretive and do not like to be around humans. What is more, the rainforest is thick with thousands of trees and plants bunched together. So, we needed to come up with creative ways to use science to count the rhinos, similar to the way a detective uses clues and logic to solve a mystery!

In the past, scientist-detectives have used clues like rhino footprints (and even rhino poop!) to estimate how many Javan rhinos live in the park. But those things cannot give a very accurate estimate. For example, how can a scientist be sure each set of footprints belongs to a different rhino? Also, poop and footprints cannot tell us about the specific areas that Javan rhinos like to hang out. Plus, what about rhinos who have not pooped or moved around in a while?! We would not be able to count them!

In other words, the clues we have been collecting were not working very well for the questions we want to answer: How many rhinos are there are? What resources do they need? And where do they like to hang out? Plus, these clues are rather smelly! So, some clever scientist-detectives have come up with a new and improved way to collect better clues: camera traps.

\section{WHAT THE HECK IS A CAMERA TRAP?!}

A few scientists put on their detective thinking caps and came up with the idea of making camera traps to count rhinos. Do not worry, it is not how it sounds-scientists are not actually trapping the rhinos in cages.

Camera traps are special, sturdy cameras that can handle the mud and muck of the rainforest (Figure 2). They do not require humans to be 
Figure 2

Camera traps are used to collect videos of Javan rhinos in their natural habitat, in order to allow scientists to count them and answer questions about the resources they need and the areas they like to spend time in.

\section{VIDEO 1}

Video of a Javan rhino from a camera trap in Ujung Kulon National Park, West Java, Indonesia.

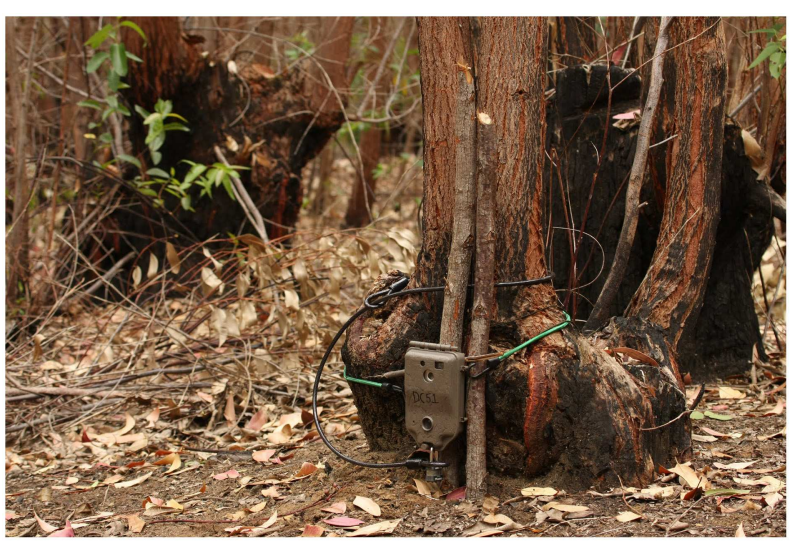

Figure 2

present to take videos. They have sensors on them that can detect the heat of an animal when it passes by, and then the camera is activated and starts filming. The animal does not know it is being filmed and goes back to its rhino business (probably wallowing in the lovely rainforest mud to keep cool, maybe eating some plants, or taking a poop the size of a small dog!). We suspect the rhinos know that something is there, and maybe even associate the cameras with humans. But they do not seem to care about the cameras being there-the presence of cameras does not appear to affect the rhinos' behavior.

The videos end up looking something like this (see Video 1).

The scientist-detectives then use these video clues to determine which rhino is which. It is a bit tricky, but think about how people have certain things on their bodies that make them unique-for example, birthmarks, height, and different hair colors. Well, rhinos have different things on their body that make them unique from other rhinos, too. Some examples of these features include horn shape, facial wrinkles, and the size of the rhino. Once the scientist-detectives knew for sure they were not counting the same rhino twice, they had a much more accurate count of the number of rhinos in the park.

It was tough to figure out exactly how many cameras were needed to gather enough clues. Each camera costs between \$100-250, plus the cost of repairs and set up. The scientists figured out that 150-200 cameras would be ideal to cover the entire area and still be affordable. Scientists think it was worth the cost, because without these cameras they would only be guessing at how many Javan rhinos there are!

So, after they figured out how many cameras they needed and got enough clues from the 178 different camera locations (Figure 3), they discovered some very interesting things about Javan rhinos! 
Figure 3

Map of where the camera traps were placed throughout the park. The different colors indicate how high up (or low) the cameras were. Scientists figured out that rhinos prefer to spend their time in the lower areas.

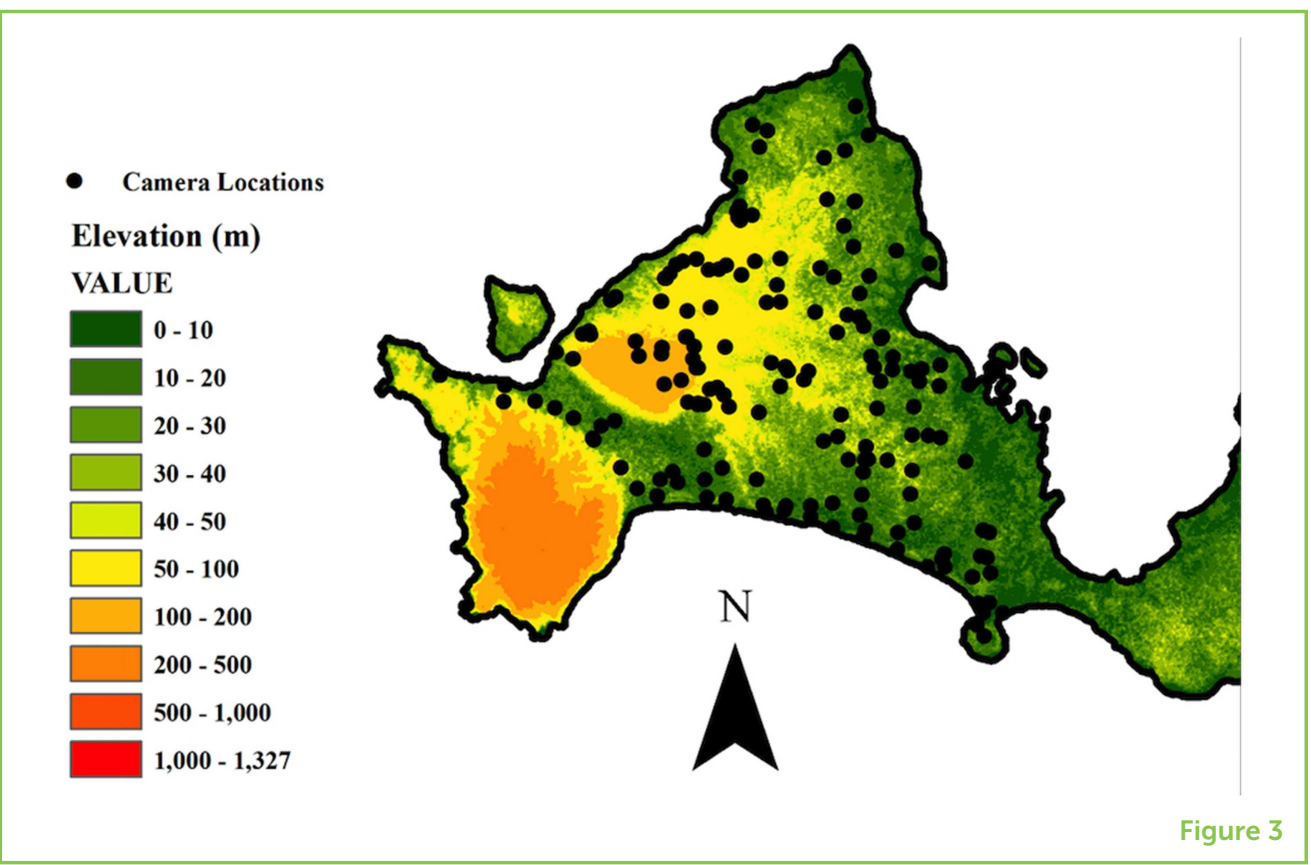

\section{WHAT DID THE SCIENTISTS DISCOVER?}

The scientists ended up getting 1,660 video clips of Javan rhinos! Using these clips, they found 22 females and 32 males. Of course, it is impossible to put a camera trap in every single spot in the park and capture every single rhino present. So, scientists used these video clues and a few different mathematical equations to estimate that there were $\sim 62$ rhinos in the park (and of those 62, there are slightly more males than females) [2]. The scientists also discovered that the closer a mud wallow is (a muddy area full of plants that rhinos like to hang out and bathe in), the more likely rhinos are to show up in that area.

In addition, the scientists discovered that Javan rhinos like to hang out in low elevation areas. Elevation refers to how high up something is - so a mountain would be high elevation, and a coastline would be low elevation. Based on the camera trap clues, it seems that the rhinos enjoy being at low elevations, near coastlines, and not high up (Figure 3). Scientists think this might be because waves crash on the coastline and create a salt spray. The salt spray builds up on the land, and rhinos like to lick the salt!

Living at low elevations puts Javan rhinos at risk for a few reasons. First, it means they are closer to contact with humans and could be harmed from human disturbance. For example, shy rhinos might spend too much of their time running away from humans. This would take away from their time eating plants and enjoying mud baths. It also means that if there is a big ocean storm (what we call a tsunami) much of their habitat could be destroyed and many of the rhinos could be killed because they are close to the water. A rhino likely cannot make it to higher ground quickly enough to escape a tsunami. 
So, if we want to come up with a solid plan to help the Javan rhinos, we can use these new clues that the scientists found. We can make what is called a conservation plan. A conservation plan is a multi-year plan that uses scientific clues to help a population of animals increase.

\section{THE NEXT MYSTERY TO SOLVE: WHAT CAN WE DO TO HELP?}

Because there is such a small number of rhinos left in only one location on earth, unexpected disasters could make the entire population disappear. For example, if there is a storm, many rhinos could be injured or killed overnight. Or, if just a few rhinos get some sort of disease, it could spread quickly to all of the other rhinos nearby. Or, if a hunter shoots the last few female rhinos, the males will roam around alone and there would not be any rhino babies. It seems grim, but this is important information for us to know!

Now the scientist-detectives have a solid estimate of the size of the Javan rhino population, the ages and sexes of the rhinos, and where they like to hang out. We can use these clues to create a new population of rhinos in a different area that is less at risk for unexpected disasters. Or, maybe we could create new habitat somewhere within Indonesia, with the necessary amount space to roam in, plants to eat, and mud to wallow in, and move some of the rhinos from the park to this new space.

There are some helpful things that you can do too! You can teach your friends and family what you have learned about the Javan rhino. You can also visit the World Wildlife Foundation website, [3] or even your local zoo, to learn more about rhinos. But maybe the most helpful thing you can do is to grow up to be a scientist-detective and solve your own science mysteries!

\section{ORIGINAL SOURCE ARTICLE}

Setiawan, R., Gerber, B. D., Rahmat, U. M., Daryan, D., Firdaus, A. Y., Haryono, M., et al. 2018. Preventing global extinction of the Javan Rhino: tsunami risk and future conservation direction. Conserv. Lett. 11:e12366. doi: 10.1111/conl.12366

\section{REFERENCES}

1. Groves, C. P., and Leslie, D. M. Jr. 2011. Rhinoceros sondaicus (Perissodactyla: Rhinocerotidae). Mamm. Species 43:190-208. doi: 10.1644/887.1

2. Setiawan, R., Gerber, B. D., Rahmat, U. M., Daryan, D., Firdaus, A. Y., Haryono, M., et al. 2018. Preventing global extinction of the Javan Rhino: tsunami risk and 
future conservation direction. Conserv. Lett. 11:e12366. doi: 10.1111/conl. 12366

3. The WWF's website on the Javan Rhino: https://www.worldwildlife.org/species/ javan-rhino

SUBMITTED: 07 February 2019; ACCEPTED: 29 August 2019;

PUBLISHED ONLINE: 19 September 2019.

EDITED BY: Becky Louize Thomas, School of Biological Sciences, Royal Holloway, University of London, United Kingdom

CITATION: Harrington ER and Gerber BD (2019) The Mysterious Case of the Disappearing Javan Rhino: Using Clues From Rhinos' Everyday Habits and Hobbies to Figure Out How to Help Them Recover. Front. Young Minds 7:121. doi: 10.3389/ frym.2019.00121

CONFLICT OF INTEREST STATEMENT: The authors declare that the research was conducted in the absence of any commercial or financial relationships that could be construed as a potential conflict of interest.

COPYRIGHT () 2019 Harrington and Gerber. This is an open-access article distributed under the terms of the Creative Commons Attribution License (CC BY). The use, distribution or reproduction in other forums is permitted, provided the original author(s) and the copyright owner(s) are credited and that the original publication in this journal is cited, in accordance with accepted academic practice. No use, distribution or reproduction is permitted which does not comply with these terms.

\section{YOUNG REVIEWERS}

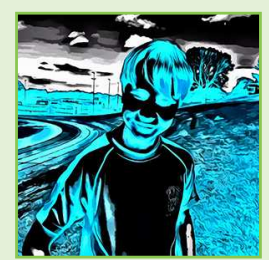

\section{FAZZ, AGE: 11}

Hi my name is Fazz, I live in Edinburgh and I enjoy rugby.

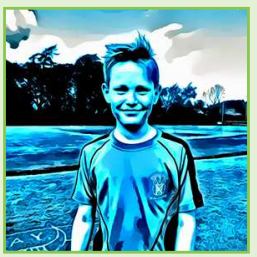

\section{LYALL, AGE: 11}

Hi my name is Lyall! I live in a family of six with two dogs in Edinburgh. I go to a great school which I have been at for 5 years now. My favorite sport is rugby, I play at least play three times a week! I really like all sports. I am really interested in this dicovery about Javan Rhinos and am really exited to find out more about them!

\section{AUTHORS}

\section{ERIN ROSE HARRINGTON}

Erin Harrington is a Ph.D. student in Biological and Environmental Sciences at the University of Rhode Island. She studies a few different things: birds and their behavior, wildlife conservation, and science communication. She also helps non-scientists 


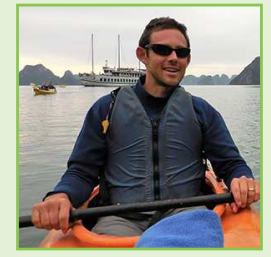

participate in scientific research projects like Project Timberdoodle. In addition, she enjoys writing about all these different research projects for people who want to learn more about science. One main goal of her Ph.D. work is to figure out ways to make science more fun and interesting for everybody! *e_harrington@uri.edu

\section{BRIAN DANIEL GERBER}

Brian Gerber is a professor at the University of Rhode Island's Department of Natural Resources Science. He studies wild animal populations across the globe, focusing on amphibians, mammals, and birds (e.g., sandhill cranes, Javan rhino, tiger, fosa, sage-grouse, boreal toad). His work aims to better understand how and why animal populations change and how we can use this knowledge to conserve species. 